\title{
ANALYSIS OF THE EFFECTIVENESS OF MAMMOGRAPHIC SCREENING IN A PINK OCTOBER CAMPAING
}

Fernando Vivian', Daniela Boeira', Bruna Kikuchi Sacchielle1, Gabriela Grechi Carrard', Luiza Herdy Boechat Luz Tiago²

'Secretaria Municipal de Saúde de Caxias do Sul - Caxias do Sul (RS), Brazil.

${ }^{2}$ Hospital Geral de Caxias do Sul, Caxias do Sul (RS), Brazil.

Introduction: The month of October was chosen to raise the population's awareness of breast cancer, with strategic actions being taken in order to optimize an early diagnosis of malignant breast lesions, as well as their treatment. The city of Caxias do Sul annually promotes a health action on a Saturday in October, known as the Pink October Campaign. The analyzed campaign was on the first Saturday of October 2017, with the operation of all Basic Health Units (UBS), and according to recommendations from the Brazilian Society of Mastology, offering mammographic evaluation and screening for women over 40 years of age. Objectives: To identify the number of diagnoses of malignant neoplasms in women who underwent screening mammography in a municipal campaign, the number of examinations performed in the campaign, and the prevalence of the BI-RADS 4 and BI-RADS 5 categories. Methods: Observational, descriptive, and retrospective study. All patients who had mammograms requested in the Pink October campaign were identified. The BI-RADS 4 and 5 cases on mammography, or after the completion of a complementary ultrasound for presenting BI-RADS 0 on the initial mammography, were referred to a reference service and had a biopsy with a posterior segment. Results: 1220 mammograms were made. In the BI-RADS 4 category, nine patients were identified (0.73\%); all had biopsies performed, and three patients had confirmed carcinoma: two of them with invasive carcinoma and one case with carcinoma in situ. There were two cases of BI-RADS 5 mammograms (0.16\%), and both had pathological confirmation of malignancy through biopsy. The prevalence of BI-RADS 4 and 5 in this population was $0.73 \%$ and $0.16 \%$, respectively. There were 126 BI-RADS 0 mammograms (10.33\%), making it possible to perform 90 complementary breast ultrasound exams. Four cases were classified as BI-RADS 4, with a negative biopsy for malignancy, and one case of BI-RADS 5, with a diagnosis of invasive lobular carcinoma. Conclusions: The Pink October Campaign held in 2017 in Caxias do Sul provided the diagnosis of six cases of breast malignancy in women between 43 and 65 years of age, one of them still in the non-invasive stage (carcinoma in situ), representing $0.49 \%$ of the population tracked in the campaign. 